\title{
Social, spatial and temporal segregation in an ant society
}

\section{Lauren E. Quevillon ${ }^{1,2^{*}}$, Ephraim M. Hanks ${ }^{1,3}$, Shweta Bansal ${ }^{4}$ and David P. Hughes ${ }^{1,2,5}$}

1 Center for Infectious Disease Dynamics, Penn State University, University Park, Pennsylvania, USA, 2 Department of Biology, Penn State University, University Park, Pennsylvania, USA, 3 Department of Statistics, Penn State University, University Park, Pennsylvania, USA, 4 Department of Biology, Georgetown University, Washington, D.C., USA 5

Department of Entomology, Penn State University, University Park, Pennsylvania, USA

*Email: leq103@psu.edu 


\section{Introduction:}

2 Sociality can be risky. A chief cost of social living is increased transmission of

3 infectious diseases, due to higher population densities combined with greater

4 contact between susceptible and infected individuals $(1,2,3,4)$. This greater

5 encounter rate has led to a growing interest in the role of social contact structure

6 in infectious disease transmission $(5,6,7,8,9,10,11)$ To capture the dynamics of

7 disease spread within dense groups, epidemiological models are shifting from

8 the principle of mass action, in which infected and susceptible individuals are

9 assumed to mix randomly, to explicitly incorporating patterns of interaction

10 through which infectious agents are transmitted (12). Understanding how

11 interactions impact epidemiology has real-world applications. The growing global

12 connectivity of human communities, coupled with closer proximity to

13 domesticated and wild populations of animals and plants, will impact the

14 incidence of infectious diseases worldwide. Thus, predicting and mitigating the

15 spread of infectious diseases by understanding transmission flow through social

16 contact networks remains a chief One Health imperative $(13,14)$.

17 Despite the increased propensity for disease transmission inherent to

18 group living, some social organisms have largely overcome this issue. Social

19 insects of the Order Hymenoptera (ants, bees, wasps) are ecologically dominant

20 in almost all terrestrial environments, despite their incredibly dense societies and

21 high degree of genetic relatedness (15). This is not for want of infectious agents-

22 social insects are host to a wide array of pathogens and parasites $(16,17,18)$.

23 Social insects are thought to overcome intense infection pressures through a 
24 series of prophylactic and inducible defenses collectively termed "social" or

25 "collective" immunity $(19,20)$. These defenses range from the immunological to

26 the behavioral, including the way colonies are organized and tasks are allocated

27 to workers $(21,22,23)$.

28 The social and spatial segregation of workers most susceptible to infection

29 is often cited as a major mechanism of disease prophylaxis in social insect

30 colonies $(24,25)$. However, it is unclear if such segregation does indeed occur.

31 We remain unsure because observing individual behavior within a realistic colony

32 has been a formidable task. Here we pursue this avenue of inquiry by testing for

33 the presence of social and spatial segregation in colonies of the carpenter ant,

34 Camponotus pennsylvanicus, using analysis of ant social networks combined

35 with individual movement data. C. pennsylvanicus is an ant species that has

36 evolved to nest inside dead trees; we mimicked this by maintaining colonies

37 inside wood under complete darkness. We focused on the oral exchange of food,

38 trophollaxis, as the key social interaction of interest because colonies must

39 balance efficient resource flow with mitigating disease spread (26). If social

40 segregation does occur, we would expect to see its signature represented in the

41 trophollactic interactions between castes.

42 Through the integration of biologically realistic behavioral observations

43 with network and spatial models centered on individual behavior, we ask if ant

44 castes are indeed segregated within the colony. Studies of social insects have

45 greatly benefitted from network analysis because it links local interactions

46 between individuals to the emergent, colony-wide properties that they produce 
$47(27,28,29)$. Several network metrics are of particular relevance to disease

48 transmission, including degree and betweeness centrality. Degree centrality, the

49 number of unique individuals that a given focal ant interacts with, summarizes

50 that individual's exposure to and potential transmission of infectious agents (11).

51 Although understanding the position of an individual within their social network is

52 important, knowing their spatial context is also crucial for disease flow. Recent

53 advances in automated tracking ability have enhanced our understanding of

54 colony-wide properties such as spatial segregation of different castes (30).

55 However, no empirical studies to date have explicitly linked individual behavior,

56 social network position, and spatial location in a single study. For this reason we

57 combine our network analyses with a statistical analysis of ant movement within

58 the nest.

59 Finally, we also study the duration and temporal order of trophollaxis

60 interactions because although network and spatial position of individuals are

61 considered important for disease dynamics, the timing of ant-ant interactions is

62 also likely important. We find a number of patterns counter to the strongly

63 prevailing view of social immunity. Within the colony conditions for disease

64 spread would appear ideal. However, by integrating network, spatial and

65 temporal views we find that barriers to disease spread likely exist. It is through

66 this integration of spatial and network analyses with time that might best inform

67 our understanding of disease flow in other complex societies. 


\section{Results:}

71 Two colonies of Camponotus pennsylvanicus, each containing 75 workers and

72 their queen, were individually housed in an experimental set-up consisting of a

73 wooden nest (area $=63 \mathrm{~cm}^{2}$ ) separated from a foraging arena (area $=63 \mathrm{~cm}^{2}$ ) by

74 a $4 \mathrm{~m}$ long maze. Inside the foraging arena, ants had ad-libitum access to $20 \%$

75 sucrose solution, water, and a protein source. This $4 \mathrm{~m}$ separation between the

76 nest and the foraging arena ensured a clear behavioral separation between ants

77 allocated to foraging versus internal nest tasks. Video filming for behavioral

78 analysis was accomplished using a video camera (GoPro Hero2 with modified IR

79 lens, www.ragecameras.com) mounted over the wooden nest illuminated under

80 infrared (IR) light. Ants are unable to perceive light in the IR end of the spectrum

81 and thus its presence was not observed to affect their behavior. Two colonies

82 were filmed over 8 consecutive nights within +/- 30 minutes of 21:00 (when $C$.

83 pennsylvanicus actively forages, L. Quevillon personal observation). An observer

84 watched this playback on a large computer monitor (size) to facilitate behavioral

85 scoring. Each individual ant was observed for trophollaxis events (two ants orally

86 exchanging liquid) for the initial 20 minutes of each recording for each night,

87 leading to a total of over 400 hours of observation (76 ants $\times 2$ colonies $\times 0.33$

88 hours $\times 8$ nights). The identities of the individuals interacting, the start and stop

89 time of their interaction, and the location of their interaction within the nest was

90 recorded. Additionally, the behavioral identity of the ant during the course of the

91 recording (ie. whether it was an active forager, inactive forager, nest worker, or

92 queen, see methods) was also recorded. 


\section{Static network analysis}

94 There was a significant difference in trophollaxis count between worker

95 types. Foragers engaged in more trophollaxis events than did either nest workers

96 or the queen, although there was no significant difference between active and

97 inactive foragers (post-hoc Tukey HSD on one-way ANOVA, Fig. 1A) However,

98 when the duration of these events is compared across worker types, nest

99 workers had on average the longest trophollaxis exchange, and this was only

100 statistically different from inactive foragers (post-hoc Tukey HSD on one-way

101 ANOVA Fig 1B).

102 Static, unweighted network analyses were conducted on the trophollaxis

103 interaction for a single colony using the package 'iGraph' (31) implemented in R

104 (32). Active foragers (ants who were observed to forage during the video

105 recording) had a higher degree (number of unique individuals with which they

106 engaged with through trophollaxis) than inactive foragers, nest workers, or the

107 queen. This represents an average of 2 additional unique individuals that

108 foragers exchanged food with compared to the queen. While the queen had an

109 average degree of 1 , the identity of the individual she interacted with was not

110 consistent across nights.

111

112 Ant movement and spatial analysis

113 For each colony, individual ant movement patterns were investigated by

114 randomly choosing five known foraging ants, five known nest workers, and the

115 queen to have their spatial movement data recorded. The wooden nest in which 
116 ants were housed was gridded to a resolution of $1 \mathrm{~cm}^{2}$, and the cell locations

117 where the majority of the ant's body was located as well as the time stamp when

118 it was in that location were recorded for the entire 20-minute duration of the video

119 for each of the 8 nights. The residence time spent in each cell was recorded and

120 summed over all ants to determine nest spatial use. In both colonies, the queen

121 Residence times in each cell and transitions to neighboring cells were used to fit

122 a continuous-time discrete-space random walk model for ant movement

123 behavior, where were used to calculate a movement or transition rate between

124 cells.

125 The average spatial usage of foragers, nest workers, and the queen is

126 given in Fig. 3. Foragers occupied a greater proportion of the nest than did either

127 non-foraging nest workers or the queen. The queen was largely immobile in both

128 colonies, though in one colony (Col10), the queen spent some time in 3 of the 4

129 chambers of the nest.

130 To test for differences in movement behavior, we used a continuous-time

131 discrete-space Markov chain model for ant movement (33) that allows for testing

132 differences in movement behavior between worker types in response to spatial

133 covariates. We tested for differences in overall mean movement rates between

134 foraging and non-foraging nest workers, and for changes in movement rates

135 when in the same chamber as the queen. We also tested for directional bias in

136 movement behavior toward or away from the queen (i.e., queen avoidance).

137 Results of this analysis show that in both colonies non-foraging ants are more

138 mobile (have higher movement rates) than are foraging ants while in the nest 
$139\left(p<10^{\wedge}-10\right.$, T-test). There was no evidence of directional queen avoidance by

140 foraging or non-foraging ants in either colony, but there was strong evidence in

141 one colony (RG2) that foraging ants move faster when near the queen then when

142 in another chamber $\left(p<10^{\wedge}-14\right.$, T-test $)$ and that non-foraging ants tend to move

143 slower when in the same chamber as the queen $(p<0.01$, T-test). In the second

144 colony (Col10), non-foraging ants also tend to move slower when near the queen

$145(p<.01$, T-test $)$, but there is small evidence that foraging ants move faster near

146 the queen $(p<.3$, T-test). This discrepancy is likely due to the increased

147 movement of the queen in the second colony, which obscures the spatial

148 movement signal.

149

150 Table 1: Inference on ant movement parameters in a continuous-time random

151 walk model of ant movement in two ant colonies (See Fig. 3)

\begin{tabular}{|c|c|c|c|c|}
\hline & Effect & Estimate & $\underline{\text { Std. Error }}$ & p-val (T-test) \\
\hline \multirow{6}{*}{$\begin{array}{l}\text { ญ్ } \\
\text { 뜨 }\end{array}$} & $\mathrm{F}$ & -2.2599 & 0.02222 & $<10^{\wedge}-15$ \\
\hline & NF & -0.92576 & 0.02035 & $<10^{\wedge}-15$ \\
\hline & $F^{*} D F Q$ & -0.19091 & 0.02453 & $<10^{\wedge}-14$ \\
\hline & $N F^{*} D F Q$ & 0.04115 & 0.01435 & 0.00416 \\
\hline & $F^{*} G D F Q$ & -0.01581 & 0.03571 & 0.65801 \\
\hline & $N F^{*} G D F Q$ & -0.00106 & 0.01023 & 0.91763 \\
\hline \multirow{6}{*}{$\begin{array}{l}\frac{0}{\overline{0}} \\
\text { 으 }\end{array}$} & $F$ & -3.18845 & 0.04111 & $<10^{\wedge}-15$ \\
\hline & NF & -1.63299 & 0.03379 & $<10^{\wedge}-15$ \\
\hline & $F^{*} D F Q$ & -0.04696 & 0.04114 & 0.25371 \\
\hline & $N F^{*} \mathrm{DFQ}$ & 0.12605 & 0.03304 & 0.00014 \\
\hline & $F^{*} G D F Q$ & -0.02391 & 0.04120 & 0.56160 \\
\hline & $N F^{*} G D F Q$ & -0.00770 & 0.03221 & 0.81119 \\
\hline
\end{tabular}

152 
154 Time-ordered (time-dependent) social network analysis

155 Social network data has traditionally been analyzed as a time-aggregated

156 or static graph, in which the timing of interactions and their order is ignored.

157 However, this timing and order is crucially important for dynamic flow processes,

158 such as disease transfer (34). We re-analyzed the ant interaction data using the

159 package 'timeordered' (35) implemented in R. This specifically incorporates the

160 time stamp of interactions when computing network metrics, and allows for a

161 much more biologically meaningful picture of intra-colony interactions of import to

162 disease. Fig. 4 shows a representative time-ordered network graph. Based on

163 the timing of interactions, returning foragers were never actually observed to

164 interact in a way necessary for disease transmission.

165 Discussion:

The results of this study provide a comprehensive view of social, spatial

168 and temporal segregation of different ant types within the colony. Static network

169 analyses revealed that actively foraging ants engage in social food exchanges

170 with more individuals than either nest workers or the queen. This is a surprising

171 finding given that actively foraging ants have the highest disease exposure of all

172 ants, and thus social immunity theory would predict that their contact with

173 susceptible nest mates should be minimized $(17,19)$. When the duration of

174 trophollaxis events is taken into account, however, there are not statistically

175 significant differences between foragers and nest workers. This could be a

176 function of the biological limits to oral food transfer in C. pennsylvanicus and is

177 worth further investigation. This component of the trophollaxis data is in 
178 accordance with what social immunity theory would predict (ie. foragers don't

179 engage long, and therefore dangerous, trophollaxis interactions with nest mates).

180 In addition to social position of ants within the colony, we were also

181 interested in the spatial activity of such ants. Analysis of nest spatial usage

182 showed that foragers are spatially promiscuous, nest workers are less so, and

183 the queen hardly moves. While the queen's lack of movement syncs well with our

184 predictions from social immunity studies, the expansive movement of the

185 foragers is counterintuitive; theory predicts that foragers should be avoiding

186 internal areas of the nest. However, in one colony (RG2), it does appear that

187 foragers may be modulating their speed in response to their social environment.

188 When foraging ants were in the same chamber as the queen, they moved faster

189 than their nest worker counterparts. By moving faster near the most important

190 individuals in the colony, foragers may be reducing the potential transmission of

191 any infectious agents that they may have been exposed to.

192 The static network analyses of colony social organization and the spatial

193 promiscuity of foragers to queens reveal an ant society not particularly well suited

194 to the prevention of disease transmission. However, the inclusion of temporal

195 data makes this situation far less dire than what it appears. When the timing and

196 order of trophollaxis interactions are taken into account, foragers and the queen

197 never interact in a way that could lead to the biologically meaningful transfer of

198 disease (ie. after a forager has come back into the nest after a foraging trip,

199 carrying some pathogen that might transfer to the queen via close proximity or

200 oral food exchange). Thus, the timing of social interactions coupled with 
201 movement rates provides evidence for behavioral prophylaxis within $C$. 202 pennsylvanicus colonies.

203 Through the incorporation of social interactions, individual movement data, 204 and the timing of social interactions, we now have a better understanding of how 205 disease prophylaxis could be accomplished in C. pennsylvanicus ant societies. 206 Had the timing of interactions and movement been ignored, a different picture 207 invalidating tenets of social immunity theory would have emerged. This provides 208 further evidence for the growing argument that temporal information and 209 meaningful behavioral interactions should be included into social network 210 analyses if we are to make biologically accurate conclusions (34). Laboratory 211 studies involving animal behavior benefit from the incorporation of environmental 212 complexity and ecological realism. We encourage the continued advancement of 213 experimental set-ups if we are to gain a true understanding of how social insect 214 societies are structured.

215 Having provided a necessary null model of colony organization in the 216 absence of disease, future experiments in which laboratory infections are 217 combined with network analyses will further inform the extent to which colony 218 organization reduces disease transmission in social insect societies. Such 219 studies will also afford us the ability to synchronize theoretical predictions from 220 agent-based modeling approaches (36) with empirical data that will allow for 221 enhanced model parameterization. Social insect societies are a powerful model 222 system for investigating how perturbations in social structure can influence 223 disease transmission dynamics. However, to realize their full potential we 
224 advocate for continued inquiry through the use of biologically meaningful

225 behavioral interactions that include temporal information.

Methods:

\section{Ant colony set-up and filming}

Two queen-right Camponotus pennsylvanicus colonies were collected from field sites in Pennsylvania, U.S.A. in December 2012. Seventy-five worker ants were haphazardly selected from each colony and were individually labeled. Labels consisted of numbers printed on photo paper that were affixed to the ants' gasters with optically clear nail polish. The labeling was not observed to alter the ants' behavior or interactions (L. Quevillon, personal observation).

The labeled ants and the queen were housed in a nest set-up consisting of a four-chambered wooden nest (total area $=63 \mathrm{~cm}^{2}$ ) that was gridded to a resolution of $1 \mathrm{~cm}^{2}$ and covered with a plexiglas top. This nest was contained within a filming box so that nest conditions were always dark. The nest was separated from a sand-bottomed foraging arena (total area $=63 \mathrm{~cm}^{2}$ ) by a $4 \mathrm{~m}$ long maze. The length of the maze ensured that there was a clear separation between workers allocated to foraging versus internal colony tasks (L. Quevillon, personal observation). Inside the foraging arena, ants had ad libitum access to water, $20 \%$ sucrose solution and mealworms.

Each colony was filmed at $+/-30$ minutes of $21: 00$ on 8 consecutive nights in June 2013 using a GoPro Hero2 camera with a modified IR filter (RageCams.com) illuminated under infrared light (Canon CMOS IR light). Infrared light, which ants are unable to perceive (reference), was not observed to affect ant behavior.

\section{Video analysis and ant worker classification}

For each night of filming, the trophollactic interactions of every ant inside the nest were individually observed. Due to degradation of IR light intensity while filming, only the first 20 minutes of each video were analyzed. For each trophollactic interaction that was observed, the ant identities, start time, stop time, and location within the nest were recorded. Additionally, the overall behavioral category of each ant on each day was recorded (i.e. nest worker, forager, non-active forager, queen). Nest workers were ants that were never observed to leave the nest, foragers were ants that actively left the nest during the course of the video segment, and inactive foragers were ants that had been witnessed to leave the nest in video segments on previous days, but which did not leave the nest during the video segment being currently analyzed. 
Trophollaxis count and duration

270

271

272

273

274

275

276

277

The number of trophollaxis events and their duration for each individual in Colony 10 was recorded as given above. To test for differences in both trophollaxis count and duration as a function of ant type (ie. forager, inactive forager, nest worker, or queen), a one-way analysis of variance was conducted using .aov in R. Post-hoc tests for differences (Tukey HSD) were then used to determine which ant types had significant differences from each other.

\section{Static network analysis}

Network metrics were analyzed for colony 10 for each night of observation. Unweighted, static network analyses were conducted using the iGraph package (31) implemented in R (32). Metrics analyzed for each individual ant included degree, betweeness centrality, closeness centrality, and Burt's constraint.

\section{Spatial movement analysis}

The time-referenced spatial locations of the queen, 5 forager ants, and 5 randomly chosen nest-worker ants were recorded for each night. We used a continuous-time discrete-space agent-based random walk model $(33,37)$ to make inference about ant movement behavior. The CTDS framework is notable in that it allows for inference on both directional (e.g., queen avoidance) and locationbased (e.g., variable movement rates in different nest chambers) movement mechanisms. Additionally, Hanks et al., (2013) have shown how inference can be made on CTDS movement models under a standard generalized linear modeling (GLM) framework, which leads to intuitive inference and efficient computation. Drawing on standard continuous-time Markov chain models (e.g., 38), if an ant is in cell $i$ at time $t$, then define the rate of transition from cell $i$ to a neighboring cell $j$ as $\lambda(i j)$. The total rate $\lambda(i)$ at which ants move (transition) out of cell $i$ is the sum of the rates to all neighboring cells: $\lambda i=\lambda i j$, and when the ant moves, the probability of moving to cell $k$ (instead of to another neighboring cell) is the ratio: $\lambda i k \lambda i$.

To model ant movement behavior near the queen, we will model $\lambda(i j)$ as a function of a spatial covariate which measures the distance from the queen's most used locations (DFQ) at each grid cell (Figure 3). To examine local behavior, the DFQ covariate was set to be constant out of the queen's chamber. The DFQ covariate is location-based and will allow us to model differences in movement rates when near or far from the queen. We also considered a directional covariate, a gradient of the DFQ covariate (GDFQ). The GDFQ gradient is a directional vector that points towards the queen, or along the direction of steepest ascent of the DFQ covariate, and the GDFQ covariate will be different for the transition rates to neighboring cells in different directions, thus allowing for directional preference in ant movement. We also consider potential 
314 differences in movement behavior between foraging $(\mathrm{F})$ and non-foraging (NF) 315 ants, with $F=1$ for foraging ants and $F=0$ otherwise, and $N F=0$ for foraging ants 316 and $\mathrm{NF}=0$ otherwise. We model the movement rate $\lambda_{k}(i j)$ of the $k$-th ant from cell $317 i$ to cell $j$ as a function of interactions of these covariates and corresponding 318 regression parameters $\{\beta\}$ :

$$
\lambda_{k}(i j)=\exp \left\{F_{k} \beta_{1}+N F_{k} \beta_{2}+\left(F_{k}{ }^{*} D F Q i\right) \beta_{3}+\left(N F_{k}{ }^{*} D F Q_{i}\right) \beta_{4}\right.
$$

Differences in overall movement rates between foragers and non-foragers will be

324 represented by differences in $\beta_{1}$ and $\beta_{2}$, with positive values corresponding to

325 higher movement rates. Positive values of $\beta_{3}$ correspond to higher movement

326 rates of foraging ants when far from the queen, and decreased movement rates

327 near the queen. Positive values of $\beta_{5}$ correspond to preferential directional

328 movement by foragers away from the queen (in the direction of the increase in

329 the gradient of DFQ). The parameters $\beta_{4}$ and $\beta_{6}$ correspond to the response of

330 non-foraging ants to DFQ and GDFQ, respectively. Hanks et al. (2013) have shown that inference on the parameters in this movement model can be accomplished using a Poisson GLM, which we fit using the 'glm' command in R. Results are summarized in Table 1.

\section{Temporal (time-ordered) network analysis}

Interactions from the static network analyses were re-analyzed including the time-stamp of when the interactions occurred. Temporal networks were constructed using the package 'timeordered' in R. The time to interaction between foraging ants and the queen was calculated using the function 'shortesttimepath'. 
bioRxiv preprint doi: https://doi.org/10.1101/002519; this version posted February 11, 2014. The copyright holder for this preprint (which was not certified by peer review) is the author/funder, who has granted bioRxiv a license to display the preprint in perpetuity. It is made available under aCC-BY-NC-ND 4.0 International license. 


\section{References:}

1. Alexander, RD. (1974) The evolution of social behavior. Annu. Rev. Ecol. Syst. 1974.5:325-383

2. Côté IM and R Poulin. (1995) Parasitism and group size in social animals: a meta-analysis.

Behavioral Ecology 6:2 (159-165).

3. Arneberg P, A Skorping, B Grenfell, and AF Read. (1998) Host densities as determinants of abundance in parasite communities. Proc. R. Soc. Lond. B 265, 1283-1289

4. Altizer S, CL Nunn, PH Thrall, JL Gittleman, Antonovics, AA Cunningham, AP Dobson, V Ezenwa, KE Jones, AP Pedersen, M Poss, and JR Pulliam. (2003) Social organization and parasite risk in mammals: integrating theory and empirical studies. Annual Review of Ecology, Evolution, and Systematics, 34: 517-547

5. Newman ME. (2002) The spread of epidemic disease on networks. Phys. Rev. E 66, 016128

6. May RM. (2006) Network structure and the biology of populations. TRENDS in Ecology and Evolution: 21(7)

7. Bansal S, BT Grenfell, and LA Meyers. (2007) When individual behaviour matters: homogeneous and network models in epidemiology. J. R. Soc. Interface 4, doi: 10.1098/rsif.2007.1100

8. Keeling, MJ \& P Rohani. (2007) Modeling infectious diseases in humans and animals. Princeton, NJ: Princeton University Press.

9. Read JM, TD Eames, and WJ Edmunds. (2008) Dynamic social networks and the implications for the spread of infectious disease. J. R. Soc. Interface 2008 5, 1001-1007

38. Keeling MJ \& KTD Eames. (2005) Networks and epidemic models. J. R. Soc. Interface 2, 295-307. (doi:10.1098/rsif.2005.0051)

10. Salathé M, M Kazandjieva, JW Lee, P Levis, MW Feldman and JH Jones. (2010) A highresolution contact network for infectious disease transmission. Proc. Nat'l. Acad. Sci. 107:51 22020-22025

11. House T and MJ Keeling. (2012) Epidemic prediction and control in clustered populations. Journal of Theoretical Biology 272: 1-7

12. Gonçalves B, Perra N and Vespigiani A. (2013) Social Networks, Contagion Processes, and the Spreading of Infectious Disease. In: Handbook of Systems Biology Concepts and Insights. Elsevier Inc.

13. Smith KP and NA Christiakis. (2008) Social networks and health. Annual Review of Sociology 34.

14. MacKenzie JS, M Jeggo, P Daszak and JA Richt [eds.]. (2013) One Health: The HumanAnimal-Environment Interfaces in Emerging Infectious Diseases. Springer-Verlag Berlin Heidelberg

15. Hölldobler B and EO Wilson. (1990) The Ants. Belknap (Harvard University Press), Cambridge, MA. 
16. Kistner DH. (1979) Social and evolutionary significance of social insect symbionts, pp. 339413 in HR Hermann [ed.], Social Insects. Academic Press, New York, Vol 1, 437 p.

17. Schmid-Hempel, P. (1998) Parasites in social insects. Princeton University Press.

18. Boomsma JJ, P Schmid-Hempel and WOH Hughes. (2005) Life histories and parasite pressure across the major groups of social insects. In: Insect evolutionary ecology, ed. F Fellowes, G Holloway and J Rolff. Wallingford, UK: CABI.

19. Cremer S, SAO Armitage and P Schmid-Hempel. (2007) Social Immunity. Current Biology 17

20. Cotter SC and RM Kilner. (2010) Personal immunity versus social immunity. Behavioral Ecology. 21:4

21. Wang D, F Moeller. (1970b) The division of labor and queen attendance behavior of Nosemainfected worker honeybees, J. Econ. Entomol. 63, 1539-1541.

22. Hart AG, \& FL Ratnieks. (2002) Waste management in the leaf-cutting ant Atta colombica. Behavioral Ecology, 13(2), 224-231.

23. Naug D and S Camazine. (2002) The role of colony organization on pathogen transmission in social insects. Journal of Theoretical Biology. 215

24. Fefferman NH, JFA Traniello, RB Rosengaus and DV Calleri. (2007) Disease prevention and resistance in social insects: modeling the survival consequences of immunity, hygienic behavior, and colony organization. Behav Ecol Sociobiol. 61:565-577

25. Cremer S and M Sixt. (2009) Analogies in the evolution of individual and social immunity. Phil. Trans. R. Soc. B 364, p.129-142

26. Blonder B, A Dornhaus (2011) Time-Ordered Networks Reveal Limitations to Information Flow in Ant Colonies. PLoS ONE 6(5): e20298. doi:10.1371/journal.pone.0020298

27. Charbonneau D, B Blonder and A Dornhaus. (2013) Social insects: a model system for network dynamics. In: P. Holme and J. Saramaki (eds.), Temporal Networks, Understanding Complex Systems, DOI 10.1007/978-3-642-36461-7 11, Springer-Verlag Berlin Heidelberg

27. Fewell JH. (2003) Social insect networks. Science 301, 1867

28. Waters JS, JH Fewell. (2012) Information processing in social insect networks. PLoS ONE 7(7): e40337. doi:10.1371/journal.pone.0040337

29. Charbonneau D, B Blonder and A Dornhaus. (2013) Social insects: a model system for network dynamics. In: P. Holme and J. Saramaki (eds.), Temporal Networks, Understanding Complex Systems, DOI 10.1007/978-3-642-36461-7 11, Springer-Verlag Berlin Heidelberg

30. Mersch DP, A Crespi and L Keller. (2013) Tracking individuals shows spatial fidelity is a key regulator of ant social organization. Science 340: 6136 1090-1093.

31. Csardi G, T Nepusz. The igraph software package for complex network research, InterJournal, Complex Systems 1695. 2006. http://igraph.org 
32. R Core Team (2012) R: A language and environment for statistical computing. R Foundation for Statistical Computing, Vienna, Austria. ISBN 3-900051-07-0, URL http://www.R-project.org/.

33. Hanks, EM, MB Hooten, and MW Alldredge. (2013) Continuous-Time, DiscreteSpace Models of Animal Movement. arXiv preprint arXiv:1211.1992.

34. Blonder B, TM Wey, A Dornhaus, R James and A Sih. (2012) Temporal dynamics and network analysis. Methods in Ecology and Evolution 3, 958-972

35. Blonder B. (2014) timeordered: Time-ordered and time-aggregated network analyses. version 0.9.4. http://cran.r-project.org/web/packages/timeordered/timeordered.pdf

36. Pie M, RB Rosengaus, JFA Traniello. (2004) Nest architecture, activity pattern, worker density and the dynamics of disease transmission in social insects. Journal of Theoretical Biology. 226 45-51

37. Hooten, MB, DS Johnson, EM Hanks and JH Lowry. (2010) Agent-based inference for animal movement and selection, Journal of Agricultural, Biological, and Environmental Statistics. 15:523-538.

38. Ross SM. (2006) Introduction to Probability Models, 9th Edition. Elsevier. 


\section{Figures:}

Figure 1: Trophollaxis data for colony 10. a) Trophollaxis count (number of individual trophollaxis events) and b) trophollaxis duration (seconds) as a function of ant worker type. * and ** denote ant worker types that differed significantly in their trophollaxis count or duration (post-hoc Tukey HSD on oneway ANOVA).

Figure 2: Representative Unweighted Static Network Graph . (Colony 10, June 3rd 2013). Circles represent individual ants; queen (black), nest workers (gray), inactive foragers (yellow), and active foragers (blue). Lines between circles represent trophollaxis interactions between those ants.

Figure 3: Segregated Use of Nest Space. Aggregated residence times in antdays for queens, active foragers, and non-foraging ants from two colonies (RG2 and Colony 10).

Figure 4: Representative Time-Aggregated Network Graph. (colony 10, June 10th, 2013). Each vertical line represents an indivdual ant, time increases up the vertical axis. Horizontal lines represent trophollaxis events between the indivudal lines that they connect. The queen is highlighted in red, and a foraging ant that has returned to the nest is highlighted in green. Note that the queen and foraging ant never interact in a temporally meaningful way, despite their overall connectivity within a static network representation. 
Figure 1

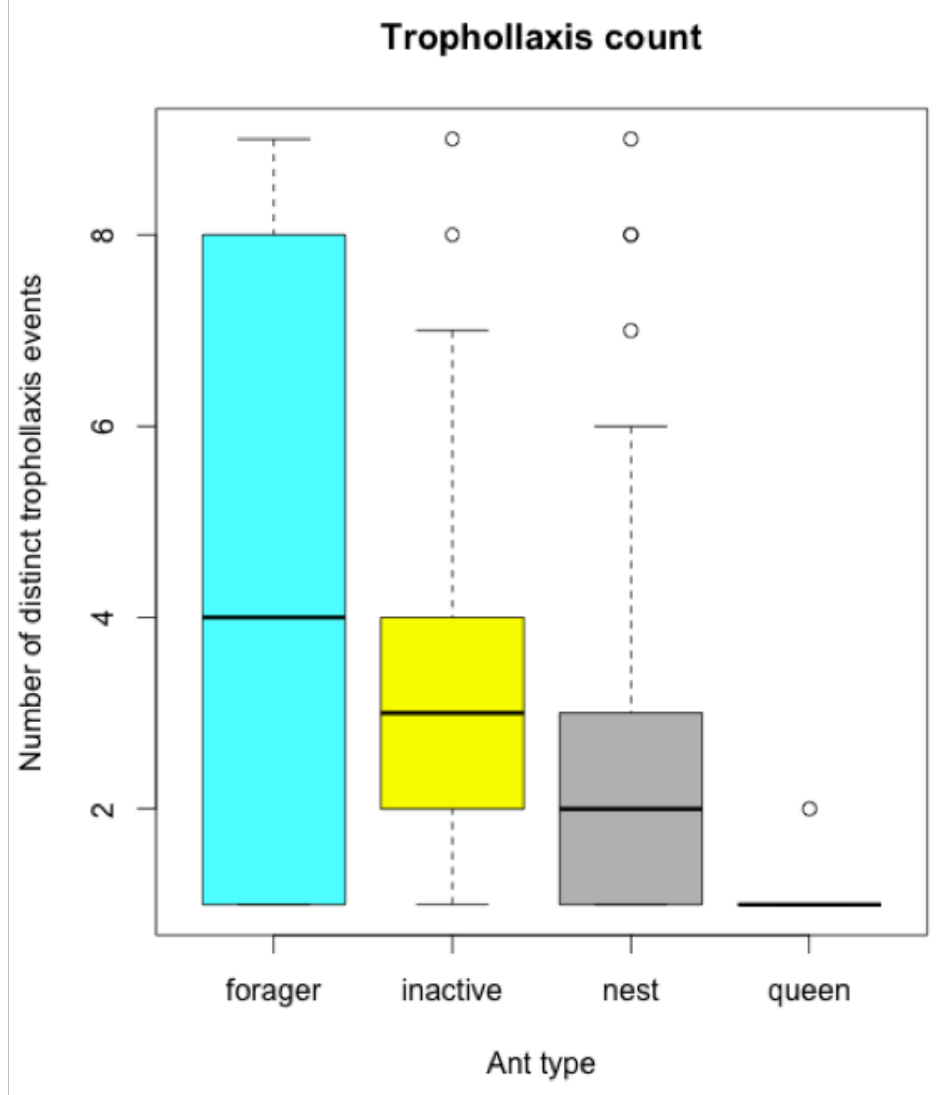

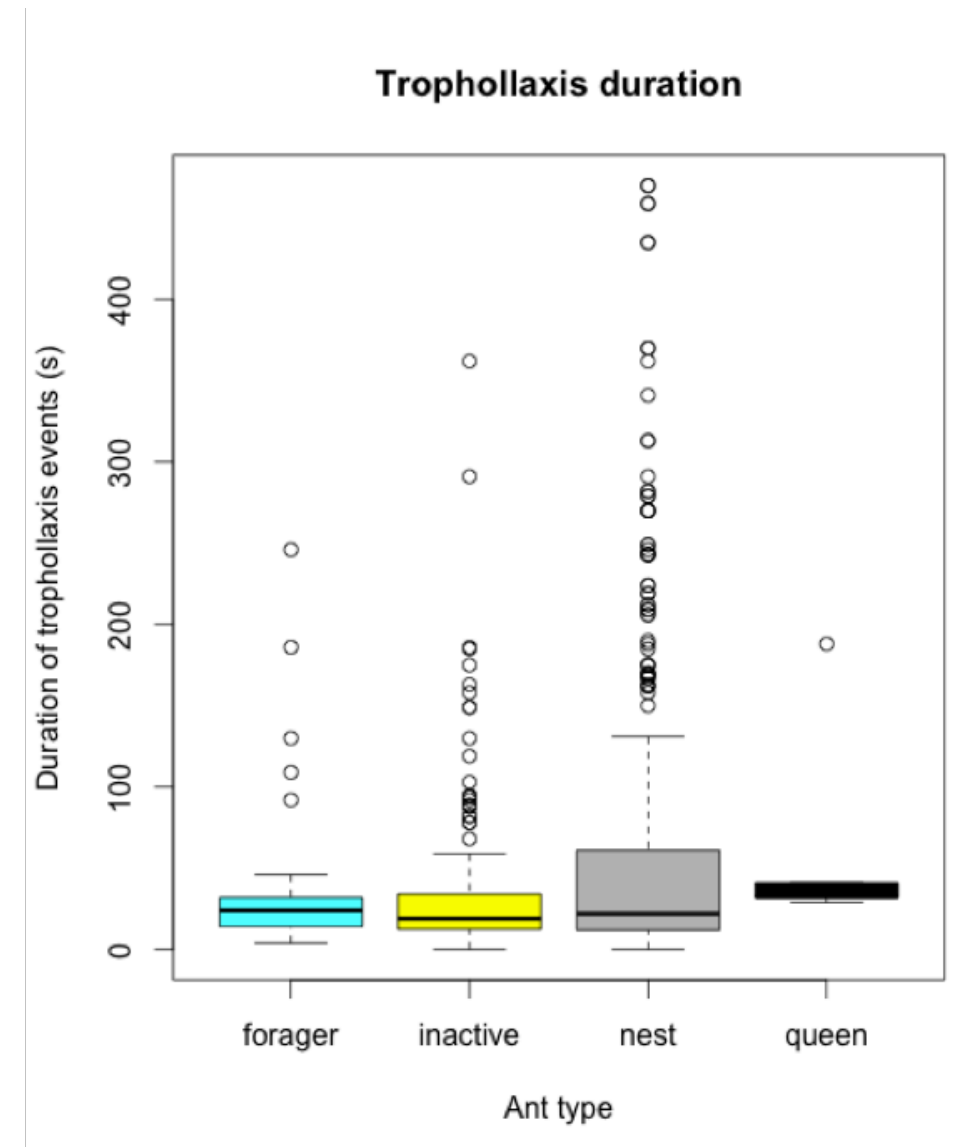


bioRxiv preprint doi: https://doi.org/10.1101/002519; this version posted February 11, 2014. The copyright holder for this preprint (which was not certified by peer review) is the author/funder, who has granted bioRxiv a license to display the preprint in perpetuity. It is made available under aCC-BY-NC-ND 4.0 International license.

Figure 2
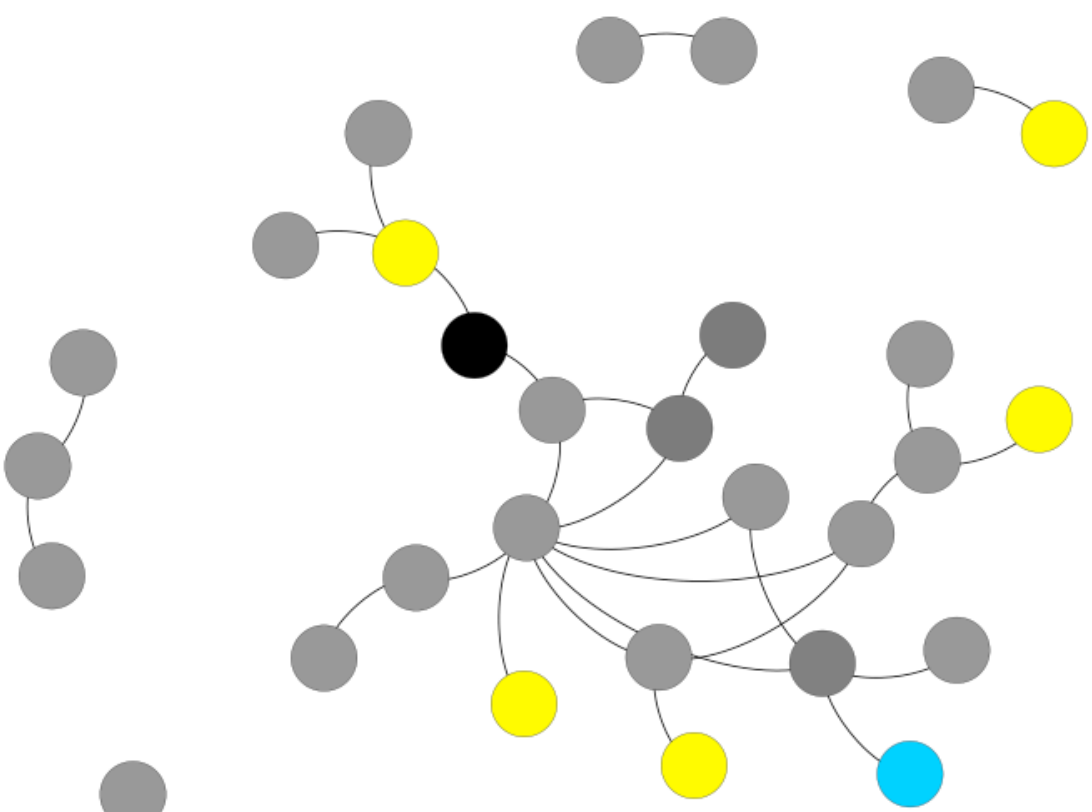
bioRxiv preprint doi: https://doi.org/10.1101/002519; this version posted February 11, 2014. The copyright holder for this preprint (which was not certified by peer review) is the author/funder, who has granted bioRxiv a license to display the preprint in perpetuity. It is made available under aCC-BY-NC-ND 4.0 International license.

\section{Figure 3}

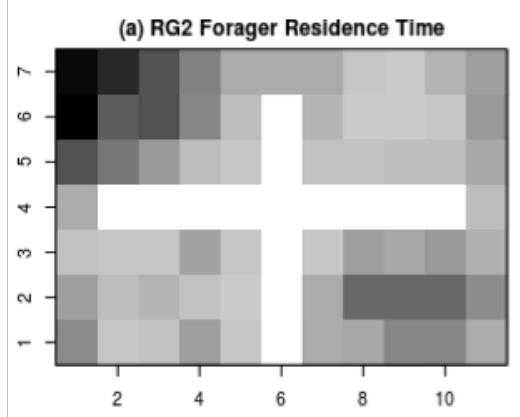

(a) Col10 Forager Residence Time

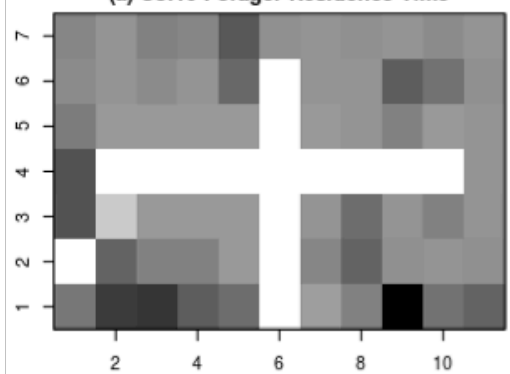

(b) RG2 Non-Forager Residence Time
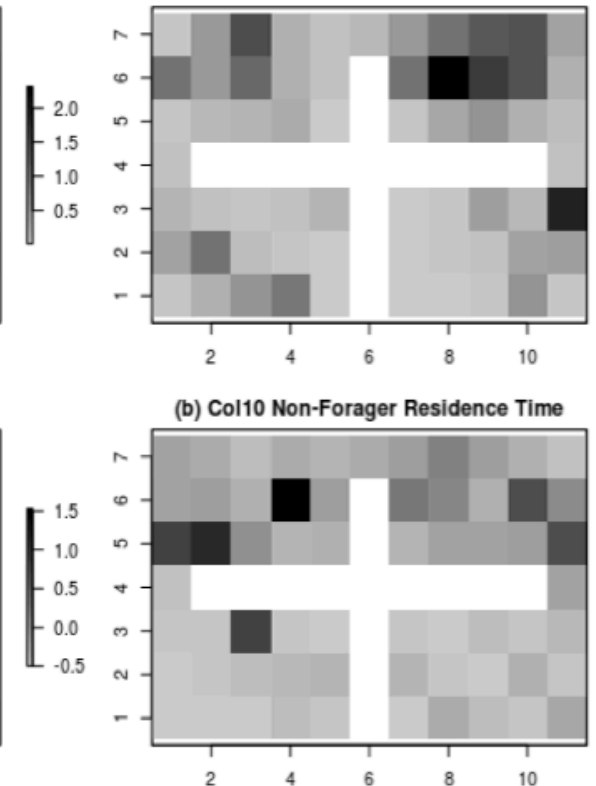

(b) Col10 Non-Forager Residence Time

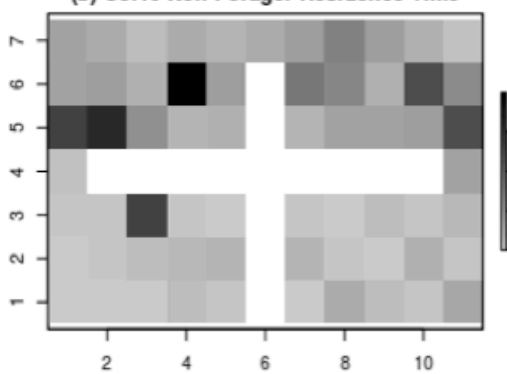

(c) RG2 Queen Residence Time

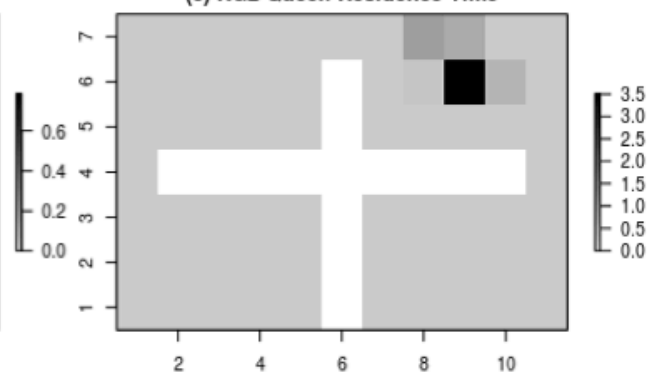

(c) Col10 Queen Residence Time

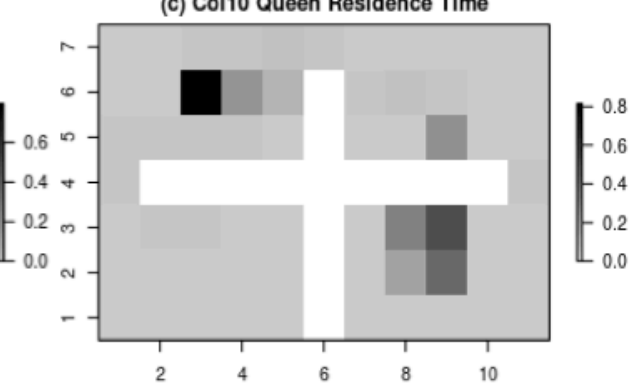


bioRxiv preprint doi: https://doi org/10.1101/002519; this version posted February 11, 2014. The copyright holder for this preprint (which was not certified by peer review) is the author/funder, who has granted bioRxiv a license to display the preprint in perpetuity. It is made available under aCC-BY-NC-ND 4.0 International license.

Figure 4

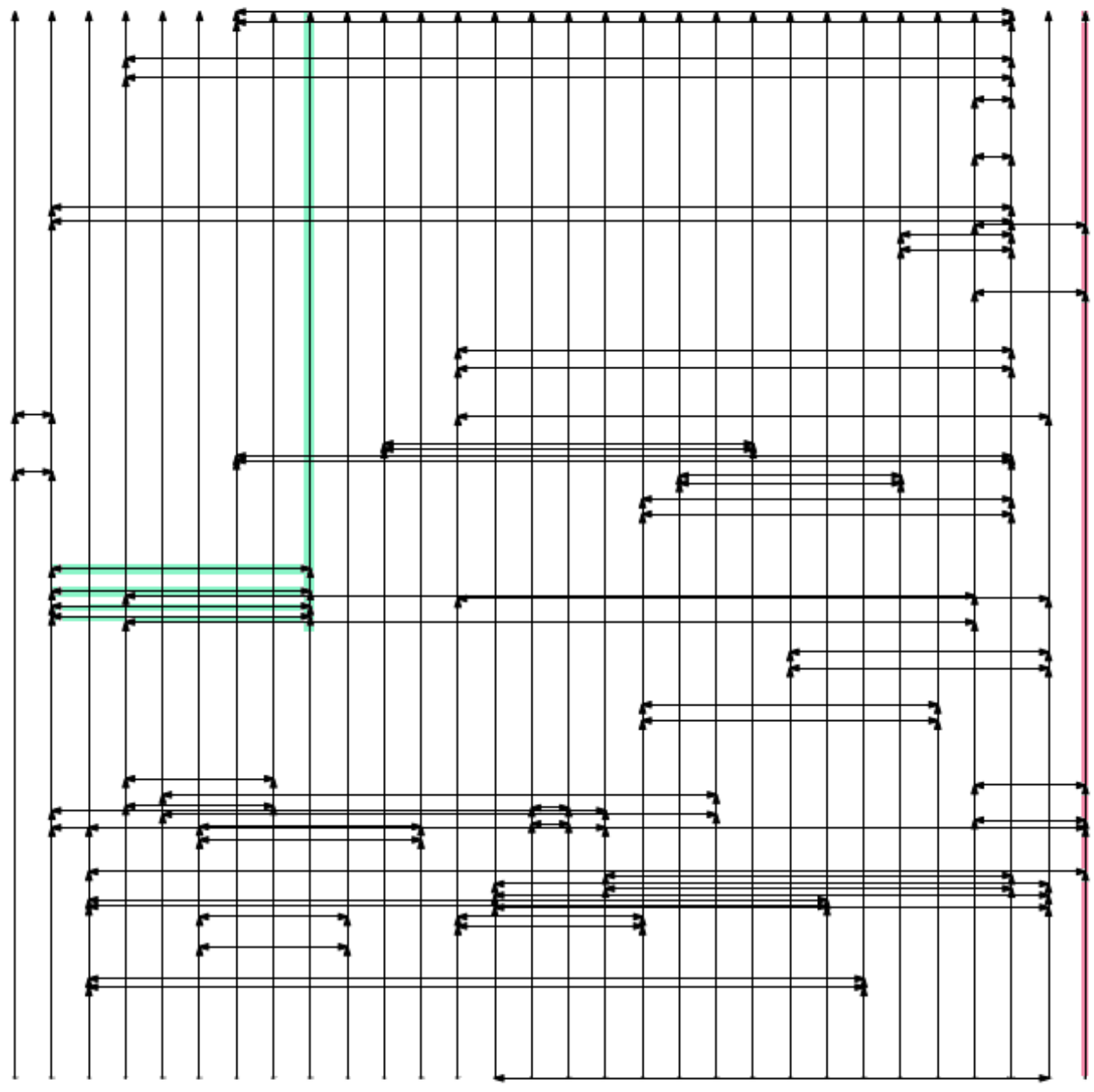

